\title{
Burrow irrigation behavior of Urechis caupo, a filter-feeding marine invertebrate, in its natural habitat
}

\author{
Christopher J. Osovitz, David Julian* \\ Department of Zoology, University of Florida, Gainesville, Florida 32611-8525, USA
}

\begin{abstract}
Urechis caupo is a burrow-dwelling filter feeder that captures suspended particles in a mucus net and irrigates its burrow with peristaltic body wall contractions. An electromagnetic flow meter was used to measure the burrow irrigation rates of $7 \mathrm{U}$. caupo in their natural burrows under normal tidal cycles. The average burrow irrigation rate of $266 \pm 158 \mathrm{ml} \mathrm{min}^{-1}$ (mean $\pm \mathrm{SD}$ ) was much greater than that typically reported in laboratory studies $\left(10\right.$ to $\left.50 \mathrm{ml} \mathrm{min}^{-1}\right)$. Periods of high irrigation activity, which probably corresponded to feeding behavior, represented $33 \%$ of the recorded behavior. These events each lasted for $13.8 \pm 4.1$ min (mean $\pm \mathrm{SD}$ ), during which time the average irrigation rate was $440 \pm 160 \mathrm{ml} \mathrm{min}^{-1}$ (mean $\pm \mathrm{SD}$ ) with a maximum sustained rate of $870 \mathrm{ml} \mathrm{min}^{-1}$. The mean pumping frequency ( 5.8 contractions $\mathrm{min}^{-1}$ ) was similar to that of laboratory studies, while the mean stroke volume $(44 \mathrm{ml})$ was comparatively high, indicating that increased stroke volume produced the high flow rates observed in our study. Based on previous density estimates $\left(61 \mathrm{~m}^{-2}\right)$, the data suggest that a population of $U$. caupo in $1 \mathrm{~m}^{2}$ of mudflat can collectively pump $23000 \mathrm{l}$ water $\mathrm{d}^{-1}$ through their burrows, of which $13000 \mathrm{l}$ is filtered through the mucus net.
\end{abstract}

KEY WORDS: Burrow irrigation · Urechis caupo $\cdot$ Filter feeding $\cdot$ Bioturbation · Invertebrate

\section{INTRODUCTION}

Many filter-feeding marine invertebrates spend their adult lives in burrows that they must irrigate almost continuously with a current of seawater to bring in suspended particles, allow gas exchange and eliminate waste products. The mechanisms of pumping water, filter-feeding and gas exchange vary among these invertebrates, but in all cases the rate of irrigation is likely to be constrained by such factors as the food availability in the water, the organism's efficiency in capturing and processing suspended food particles, the concentration of dissolved $\mathrm{O}_{2}$, and the metabolic cost of pumping water through the burrow, through the filtering structure, and around the animal.

Because many burrow-dwelling, filter-feeding animals can capture virtually all suspended material from

*Corresponding author. Email: julian@zoo.ufl.edu the seawater, their feeding activity broadly impacts the local environment. In addition to removing plankton from the water column (e.g. Vedel \& Riisgård 1993), the continuous flow of seawater into their burrows increases the thickness of the oxidized layer available to other sediment-dwelling coastal animals (Anderson \& Meadows 1978, Meyers et al. 1987, Fenchel 1996). Yet despite this potentially significant impact on coastal ecosystems, the behavior of burrow-dwelling marine invertebrates has rarely been measured under natural conditions. Furthermore, for most burrowdwelling marine invertebrates it is not yet clear that irrigation behavior under experimental conditions is representative of behavior under natural conditions. While the irrigation activity of burrow-dwelling invertebrates has been carefully studied in the field in artificial burrows, as well as under laboratory conditions in artificial burrows and in sediment tanks (e.g. Riisgård 1989, 1991, Vedel \& Riisgård 1993, Riisgård \& Banta 1998), in only very few studies has burrow irrigation 
behavior been measured in the field in natural burrows (i.e. Krüger 1964 for Arenicola marina and Grove et al. 2000 for Chaetopterus variopedatus).

In this study, we used an electromagnetic flow meter to measure the burrow irrigation behavior of the burrow-dwelling, filter-feeding echiuran worm Urechis caupo (Fisher \& MacGinitie 1928) in its natural burrow. $U$. caupo is a large (50 to $100 \mathrm{~g}$ ) animal found in mudflats along the west coast of the United States. It is a permanent resident of a $\mathrm{U}$-shaped burrow, through which it pumps seawater using anterior-to-posterior peristaltic contractions of its body wall (so-called 'piston pumping'). This water current is periodically filtered through a mucus net that is secreted by specialized glands near the worm's proboscis. This mucus net efficiently captures suspended matter from the irrigation current, including macromolecules as small as $4 \mathrm{~nm}$ in diameter (MacGinitie 1945). At intervals, $U$. caupo consumes its net, thereby ingesting all captured particles, after which it creates a new net and begins the process again (Fisher \& MacGinitie 1928, Hall 1931, MacGinitie 1945, Julian et al. 2001). In some locations, $U$. caupo is the dominant member of the mudflat macrofauna, reaching densities of $61 \mathrm{~m}^{-2}$ (Arp et al. 1992). Although the irrigation behavior of $U$. caupo under laboratory conditions has been well studied (Hall 1931, Jørgensen 1955, Lawry 1966, Pritchard \& White 1980, Jørgensen et al. 1986, Julian et al. 2001), its irrigation behavior in the field in a natural burrow has never been investigated.

\section{MATERIALS AND METHODS}

We measured the burrow irrigation activity of 7 Urechis caupo at the Elkhorn Slough National Estuarine Research Reserve in Monterey Bay, California, during June 2001, March 2002 and April 2002. For this report, the data from each worm are coded with a number corresponding to that worm's sequence in the study (Worm \#1, 22 June 2001; \#2, 23 June 2001; \#3, 28 March 2002; \#4, 30 March 2002; \#5, 31 March 2002; \#6, 2 April 2002; \#7, 4 April 2002). Water flow was measured with an electromagnetic flow system (Carolina Medical 501 electromagnetic flow meter with an EP 625 flow probe of $8 \mathrm{~mm}$ inner diameter). The flow probe was attached to a funnel that was partially buried in the sediment at one end of a worm's burrow such that all water flow into or out of the burrow passed through the funnel and probe lumen. The probe allowed the detection of irrigation flow rate and flow direction. Another funnel was placed over the other burrow opening to ensure that the 2 burrow openings were at the same height. The flow meter's voltage output was either digitized at $8 \mathrm{~Hz}$ using a 10-bit data acquisition system (Dataq Instruments DI-194) and stored directly on a notebook computer for Worms \#1 and \#2, or it was digitized and stored at $2 \mathrm{~Hz}$ on a 12-bit data logger (Omega IQ-40) for Worms \#3 to \#7. The flow meter and computer were placed inside a watertight case (Pelican Products) that was supported on a stand constructed of PVC pipe to keep the equipment above the seawater level. The flow probe cable was exported through the watertight case via a bulkhead fitting with a watertight seal.

During low tide, the experimental equipment was prepared above the openings of a Urechis caupo burrow. Prior to mounting the flow probe onto one of the burrow openings, the probe was calibrated by draining seawater from an elevated container through vinyl tubing and through the probe, with the true flow rate through the probe being determined with a graduated cylinder. The recording was started $45 \mathrm{~min}$ after the incoming tide had submerged the burrow openings (to ensure that wave action did not cause the openings to become exposed during a recording) and was terminated 3 to $6 \mathrm{~h}$ later when the battery was exhausted or the tide reached the level of the electronic equipment (whichever occurred first). During the recording, the water temperature was measured periodically using a thermometer. At low tide on the following day, the worm was obtained from its burrow and weighed (the worms were left out of seawater for at least $30 \mathrm{~min}$ prior to weighing to ensure that the worm's hindgut would be drained of seawater).

Data analysis. Contraction frequency, periodicity and stroke volume were analyzed using custom peakdetection software, set to catalog the location of any data point in the flow data preceded by an uninter-

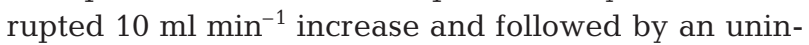
terrupted $10 \mathrm{ml} \mathrm{min}{ }^{-1}$ decrease. Since the maximum contraction frequency was rarely more than $0.2 \mathrm{~Hz}$, records obtained at $8 \mathrm{~Hz}$ (Worms \#1 and \#2) were reduced to $2 \mathrm{~Hz}$ by box-averaging prior to analysis. Means are presented $\pm 1 \mathrm{SD}$. Statistical comparisons of means were analyzed using paired $t$-tests, and correlations were analyzed using least-squares linear regression, with probabilities less than 0.05 considered to be significant. When means from multiple animals are described as being significantly different, the least significant $\mathrm{p}$-value is presented.

Estimation of increased irrigation cost due to the flow probe. While a thorough consideration of the theoretical burrow irrigation cost is complex and beyond the scope of this study (see Riisgård \& Larsen 1995 for a detailed review), an estimate of the relative increase in total flow resistance caused by the probe was calculated after making the following 4 simplifying assumptions. First, the dimensions of a typical Urechis caupo burrow were assumed to be $2.5 \mathrm{~cm}$ inner diameter and 
$100 \mathrm{~cm}$ in length, with 2 narrowed burrow openings at each end, each $1 \mathrm{~cm}$ diameter and $1 \mathrm{~cm}$ length (pers. obs.). Second, the worm was assumed to have a tissue volume of $60 \mathrm{~cm}^{3}$ (ca. $60 \mathrm{~g}$ wet mass) and to have an average hindgut inflation volume of $0.4 \mathrm{~cm}^{3} \mathrm{~g}^{-1}$, for a total worm volume of $84 \mathrm{~cm}^{3}$ (Julian \& Arp 1992). Third, the worm was assumed to move the water as a piston pump with no leakage (e.g. Riisgård \& Larsen 1995), with the piston (the portion of the worm in direct contact with the burrow wall) initially forming at the anterior of the worm, with a length of $3 \mathrm{~cm}$ (Jørgensen et al. 1986). The volume of the annulus created between the remaining, posterior portion of the worm's body and the burrow wall around it thereby defines the stroke volume, which was assumed to be $45 \mathrm{~cm}^{3}$ (based on the present study). Fourth, the flow was assumed to be steady state, laminar and fully developed (Gursul 1998). The burrow, burrow openings and flow probe ( $8 \mathrm{~mm}$ diameter, $4.5 \mathrm{~cm}$ length) were then modeled as straight tubes in series, and the worm was modeled as 2 cylinders in series (the piston and the portion posterior to the piston) that were coaxial to the burrow. The relative difference in hydrostatic pressure required to pump water through the complete system, both with and without the flow probe, was estimated from the Hagen-Poiseuille equation, which was applied to the probe, the burrow openings and the portions of the burrow without a worm, and the derivation Hagen-Poiseuille equation for a concentric circular annulus (Gursul 1998), which was applied to the nonpiston portion of the worm. The resistance due to each component in the system is presented as a fraction of the total resistance, which is proportional to the total hydrostatic pressure drop.

\section{RESULTS}

The burrow irrigation behavior of all 7 Urechis caupo was variable, both between and within worms. Three representative records of irrigation activity for Worms $\# 1$, \#6 and \#7 are presented in Fig. 1. Three worms $(\# 1$, \#3 and \#5) pumped at both moderate $(126 \pm 17 \mathrm{ml}$ $\left.\mathrm{min}^{-1}\right)$ and high $\left(366 \pm 113 \mathrm{ml} \mathrm{min}^{-1}\right)$ rates for sustained periods, 3 other worms (\#4,\#6, and \#7) pumped at high rates almost continuously, and the remaining worm (\#2) continuously pumped at relatively low rates. Among all of the recordings, only 6 periods of very low irrigation rate $\left(19 \pm 14 \mathrm{ml} \mathrm{min}^{-1}\right)$ were observed, none of which lasted longer than $8 \mathrm{~min}$. The irrigation rate of the least active individual (\#2) averaged $41 \mathrm{ml} \mathrm{min}^{-1}$, while the irrigation rate of most active individual (\#7) averaged $517 \mathrm{ml} \mathrm{min}^{-1}$. The average irrigation rate of all 7 worms was $266 \pm 158 \mathrm{ml} \mathrm{min}^{-1}$. Four worms (\#2, $\# 3$, \#4 and \#5) irrigated their burrows in one direction

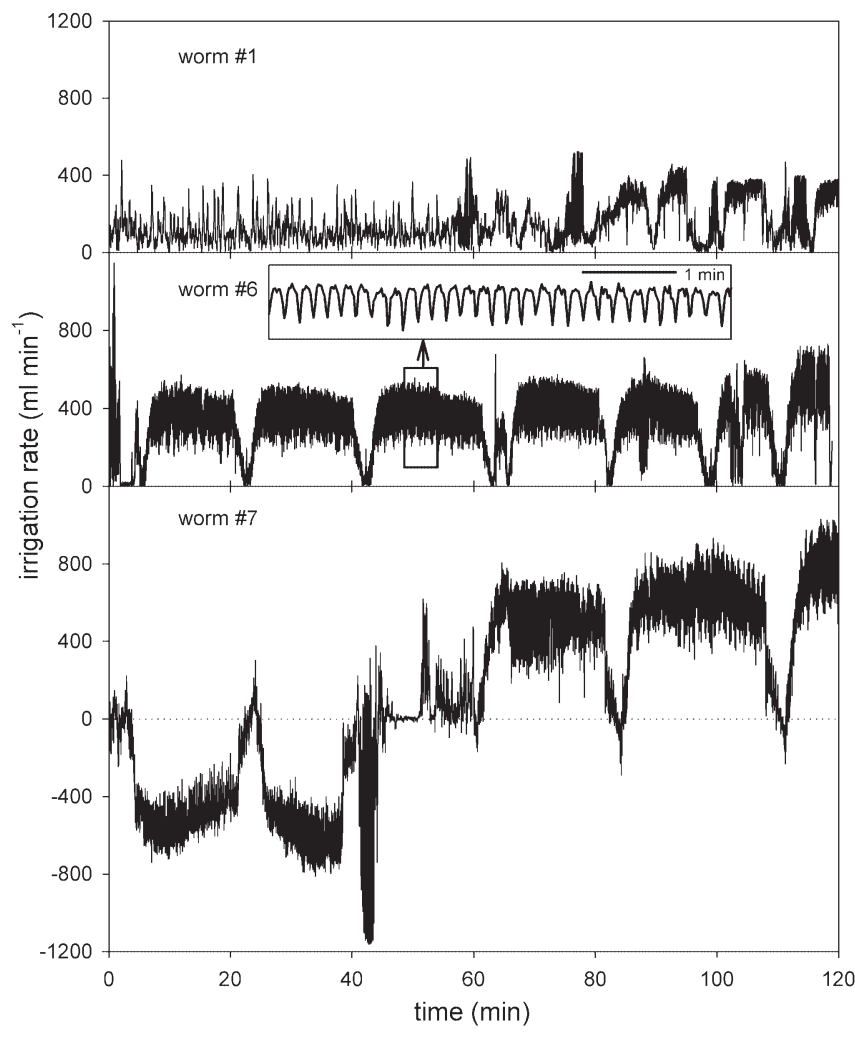

Fig. 1. Urechis caupo. Three representative $2 \mathrm{~h}$ segments of burrow irrigation behavior for U. caupo. Periods of sustained high activity punctuated by short periods of low activity are presumed to be feeding periods. While Worm \#1 fed only toward the end of the segment, Worms \#6 and \#7 fed almost continuously. The inset in \#6 represents a 5 min close-up view of a presumed feeding period within the box. The graphs of Worms \#1 and \#6 show absolute values and no negative irrigation values. To illustrate a reversal of position in the burrow, the graph of Worm \#7 shows a change in pumping direction as the net irrigation rate changes from negative to positive between 40 and 60 min

throughout the recording period, while the remaining worms (\#1, \#6, and \#7) changed the direction of the irrigation current at least once, presumably accomplished by reversing its position in the burrow. For the first 2 worms (\#1 and \#2), the ambient water temperature during the recording periods was $19^{\circ} \mathrm{C}$, while it was $13^{\circ} \mathrm{C}$ for the recording periods of the remaining worms. An insufficient number of worms were recorded at the higher temperature to determine whether any differences in irrigation behavior might have been temperature dependent.

Among all worms, the average pumping frequency was $5.8 \pm 1.3$ contractions $\mathrm{min}^{-1}$ and the stroke volume was $44 \pm 23 \mathrm{ml}$. For 6 of the 7 worms, periods of high irrigation activity that extended for many minutes were recorded. These periods, henceforth referred to as 'sustained high-activity periods', accounted for 33\% 


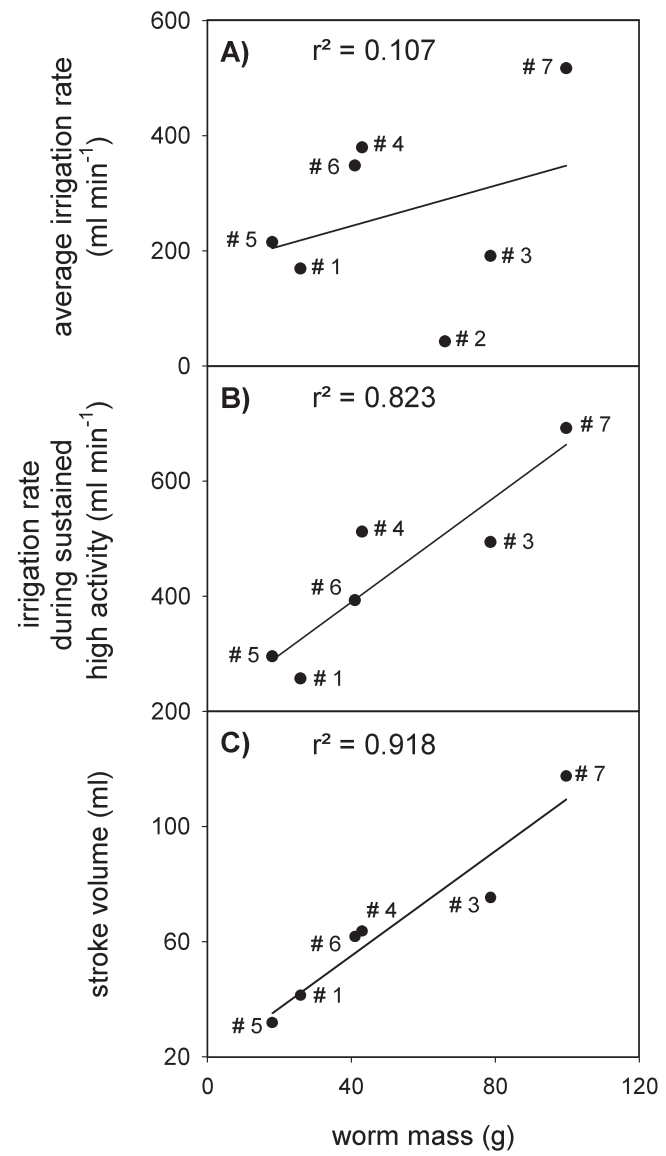

Fig. 2. Urechis caupo. Correlation of burrow irrigation parameters with body wet mass (g) for U. caupo. (A) Total average irrigation rate as a function of wet mass $(n=7)$. (B) Average irrigation rate during sustained high activity (which is assumed to be feeding behavior) as a function of wet mass $(\mathrm{n}=6)$. (C) Average stroke volume during sustained high activity as a function of wet mass $(n=6)$. Numbers next to data points correspond to that worm's identification code, as used throughout the text. Note that Worm \#2 is not included in (B) or (C) since it did not show a sustained high-activity period during the recording period of the total study time and resembled prior descriptions of feeding behavior (Fisher \& MacGinitie 1928, Hall 1931, Jørgensen 1955). On average, each period lasted for $13.8 \pm 4.1 \mathrm{~min}$, during which the irrigation rate was $440 \pm 160 \mathrm{ml} \mathrm{min}^{-1}$, the stroke volume was $65 \pm 30 \mathrm{ml}$, and the frequency was $6.8 \pm 0.8$ contractions $\mathrm{min}^{-1}$. The irrigation rates during these periods were extremely high. For example, during one sustained highactivity period, Worm \#7 maintained an average flow rate of $870 \mathrm{ml} \mathrm{min}{ }^{-1}$ for $20 \mathrm{~min}$. Of the sustained highactivity irrigation periods, $60 \%$ were followed by subsequent sustained high-activity irrigation periods within $5 \mathrm{~min}$. Animal mass was not correlated with average irrigation rate $\left(r^{2}=0.107, p=0.47\right.$; Fig. 2 A) but was strongly correlated with both irrigation rate $\left(\mathrm{r}^{2}=\right.$ 0.823; $\mathrm{p}<0.05$; Fig 2B) and stroke volume $\left(\mathrm{r}^{2}=0.918\right.$, $\mathrm{p}<0.005$; Fig 2C) during sustained high activity.

For all worms except Worm \#4, stroke duration (the inverse of frequency) was significantly correlated with stroke volume $(\# 4, \mathrm{p}=0.73$; all other worms, $\mathrm{p} \leq$ $0.0024)$. To examine differences between different irrigation behaviors, we separated stroke data that were contained within sustained high-activity periods (aver-

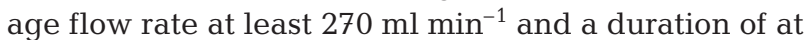
least $5 \mathrm{~min}$ ) into a separate category from all other flow data (Fig. 3). Both the average stroke volume and frequency of the high-activity periods were significantly different from the remaining data $(p \leq 0.006)$. For all 7 worms, stroke volume was significantly correlated with stroke duration during the high-activity periods ( $p \leq 0.0007$ ). Both stroke volume and duration of the high-activity periods were significantly different from those of the remaining data $(p<0.0001)$, except for the stroke duration of Worm \#7 ( $p=0.39)$, which pumped predominantly at high rates.

Based on the mathematical model of flow resistance through the burrow of Urechis caupo, the electromagnetic flow probe produced $18 \%$ of the total flow resis-

Table 1. Urechis caupo. Comparison of published studies that report irrigation rates of $U$. caupo. n: number of worms for which data were reported; na: information was not available. Note that the measurement device used by Lawry (1961) did not allow accurate recordings of pumping frequencies above $1 \mathrm{~min}^{-1}$. Jørgensen et al. (1986) report corrections of values originally presented in Jørgensen (1955)

\begin{tabular}{|lccccc|}
\hline $\mathrm{n}$ & $\begin{array}{c}\text { Irrigation rate } \\
\left(\mathrm{ml} \mathrm{min}^{-1}\right)\end{array}$ & $\begin{array}{c}\text { Stroke volume } \\
(\mathrm{ml})\end{array}$ & $\begin{array}{c}\text { Pump frequency } \\
\left(\mathrm{min}^{-1}\right)\end{array}$ & $\begin{array}{c}\text { Temperature } \\
\left({ }^{\circ} \mathrm{C}\right)\end{array}$ \\
\hline 2 & 13.9 & na & na & 16.9 & Hall (1931) \\
1 & 20 & na & na & 13 & Lawry (1966) \\
13 & 45 & 7.6 & 5.9 & 19.5 & Pritchard \& White (1980) \\
1 & 213 & 11 & 8.5 & 20 & Jørgensen et al. (1986) \\
12 & 27 & 44 & 5.6 & 14 & Julian et al. (2001) \\
7 & 266 & & & 13 (Worms \#1 and \#2) & This study \\
\hline
\end{tabular}



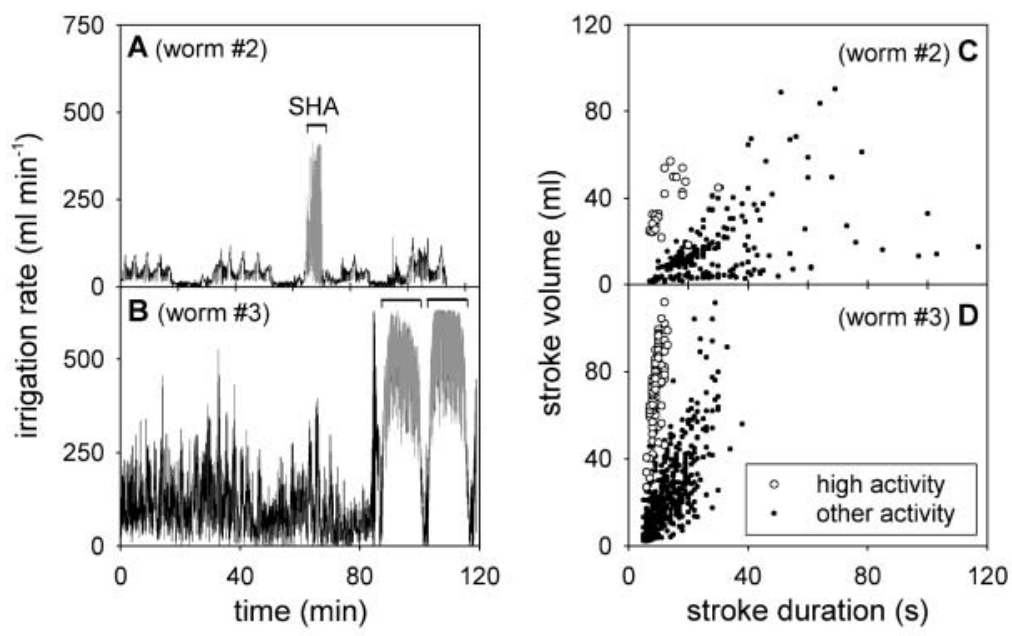

Fig. 3. Urechis caupo. Pumping behavior of 2 U. caupo (Worms \#2 and \#3) during periods of high burrow irrigation activity (defined as irrigation rate of at least $270 \mathrm{ml} \mathrm{min}{ }^{-1}$, duration at least $5 \mathrm{~min}$ ). (A,B) Burrow irrigation rate $\left(\mathrm{ml} \mathrm{min}^{-1}\right)$, with gray segments and brackets over the data indicating periods of sustained high activity (SHA). Note that the first brief period of high irrigation activity seen in Worm \#3 (B) did not satisfy the criteria for sustained high activity, and was therefore not included in the analysis. $(C, D)$ Correlation of stroke volume with stroke duration (inverse of stroke frequency), with open circles indicating periods of sustained high activity. Stroke volume and stroke duration were correlated in both worms during high activity ( $\left.\# 2, \mathrm{r}^{2}=0.33, \mathrm{p}=0.0007 ; \# 3, \mathrm{r}^{2}=0.42, \mathrm{p}<0.0001\right)$ and during the remaining activity $\left(\# 2, \mathrm{r}^{2}=0.02, \mathrm{p}=0.0024 ; \# 3, \mathrm{r}^{2}=0.22, \mathrm{p}<0.0001\right.$ )

tance. In comparison, the annulus around the worm, the natural burrow openings, and the remainder of the burrow produced 78,2 and $3 \%$ of the total flow resistance, respectively.

\section{DISCUSSION}

The average burrow irrigation rate of Urechis caupo was greater than that measured in all previous studies (Table 1). Furthermore, although the average pumping frequency was similar to that reported previously, the average stroke volume was much greater. Therefore, stroke volume rather than stroke frequency probably accounts for the high irrigation rates observed in the field. The relatively invariant frequency is consistent with the existence of a pacemaker (Lawry 1966) that is relatively insensitive to environmental conditions or physiological state (Julian et al. 2001). Nonetheless, while the average stroke frequencies were similar among worms in this study, there was some variability within worms. This is especially evident when comparing sustained high-activity periods with the remaining activity periods, between which individual $U$. caupo changed both stroke volume and stroke duration (and therefore frequency; Fig. 3C,D). This is consistent with a previous laboratory study of $U$. caupo, in which irri- gation rate, stroke frequency and stroke volume were elevated when a worm was pumping water through its mucus net (Julian et al. 2001), but it is in contrast to Nereis diversicolor, in which stroke volume appears relatively invariant at a given back pressure (Riisgård 1991, Riisgård et al. 1992). Since stroke volume during sustained high activity was strongly correlated with the worm's mass, U. caupo may be pumping near its maximum sustained irrigation rate during the high-activity periods. Stroke frequency during sustained high-activity periods was very similar among worms, further suggesting that these rates are limited more by the worm's maximum stroke volume, and therefore the worm's size.

Several factors could explain the lower burrow irrigation rates observed in laboratory studies of Urechis caupo compared with our field measurements. First among these is the increased hydrostatic pressure required to pump water through the flowmeasuring device. The theoretical calculations predict that the electromagnetic flow probe constituted $18 \%$ of the total flow resistance (and therefore $18 \%$ of the hydrostatic pressure drop across the system), which is relatively small. The presence of the mucus net during feeding would be expected to further increase resistance. While this resistance has never been determined for $U$. caupo, the mucus feeding structure has been estimated to increase the total hydrostatic pressure by $100 \%$ for Chaetopterus variopedatus (Riisgård 1989) and by $38 \%$ for Nereis diversicolor (Riisgård et al. 1992). Therefore, the relative increase in resistance due to the flow probe would be even less during feeding. By comparison, the flow measurement systems used in most laboratory studies of $U$. caupo consisted of lengths of tubing added to the burrow openings, which probably added substantially more resistance than the electromagnetic flow probe. Interestingly, the only laboratory study of $U$. caupo to report irrigation rates comparable to ours was Jørgensen et al. (1986), which gives a correction of the flow values first reported in Jørgensen (1955; Table 1). In that study, Jørgensen did not measure irrigation, but instead observed the dimensions of a worm in a glass tube while it was pumping water through the tube, presumably in the absence of added flow resistance. Based on these visual measurements, Jørgensen reported an irrigation rate of $213 \mathrm{ml} \mathrm{min}^{-1}$, a stroke volume of $25 \mathrm{ml}$, and a pumping frequency of $8.5 \mathrm{~min}^{-1}$. While the irrigation rate of $213 \mathrm{ml} \mathrm{min}^{-1}$ is within the range reported in our 
study, it is the result of a comparatively high pumping frequency, which may be because Jørgensen apparently measured irrigation rates during feeding behavior.

A second factor that could explain the lower average irrigation rates in some laboratory studies is inactivity of the worm. Fisher \& MacGinitie (1928) and Hall (1931) reported long periods (from 20 to $60 \mathrm{~min}$ or more) during which Urechis caupo kept in the laboratory were completely inactive. In contrast, we found only 6 periods of inactivity or very low activity within all 7 field recordings, and these were all of short duration $(<8 \mathrm{~min})$. However, this alone could not explain the lower irrigation rates in the laboratory, since some laboratory studies also reported only rare periods of inactivity (Lawry 1966, Pritchard \& White 1980, Julian et al. 2001). Finally, a third factor that might explain the lower irrigation rates in the laboratory is that ours is the only study of $U$. caupo in its natural environment and natural burrow. Therefore, this study is free from laboratory manipulations or suboptimal conditions that might have disturbed the worms' normal behaviors, such as inappropriate or absent food, the absence of natural tidal cycles, abnormal lighting conditions, the absence of its normal burrow commensals, and perhaps most importantly the practice of keeping the animal in an artificial glass or plastic tube that has a uniform diameter and a very smooth interior surface. It is not known to what extent each of these factors might have contributed to the higher irrigation rates observed in our study, but it would be interesting to determine whether $U$. caupo will display normal irrigation behavior in the laboratory if one or more of these factors are corrected.

It is not yet clear why burrow irrigation behavior in Urechis caupo is much more sensitive to laboratory conditions, especially because at least some burrowdwelling marine invertebrates have irrigation rates in the laboratory that are similar to those of that species in the field in natural burrows. Krüger (1964) used a temperature-sensing flow probe to measure the irrigation rate of Arenicola marina in the field in natural burrows, and reported values similar to previous laboratory measurements. Similarly, Grove et al. (2000) used a Doppler flow probe to measure irrigation rates of Chaetopterus variopedatus in the field in natural burrows, which were also similar to laboratory measurements. Additionally, the frequency of pumping, and presumably the irrigation rate, of Nereis diversicolor is similar whether the animal is maintained in glass tubes in the field, in glass tubes in the laboratory, or in sediment burrows in the laboratory (Riisgård et al. 1992, Vedel et al. 1994). In all of these studies, the measuring equipment probably added very little flow resistance (although this is difficult to confirm for the A. marina study), but there may be additional explanations for the similarities between laboratory and field recordings for at least some of these species. Unlike $U$. caupo, A. marina is a deposit feeder that lives in a J-shaped tube and pumps water through the sediment at one end of its burrow. Therefore, A. marina may be less sensitive to changes in flow resistance and burrow shape encountered in laboratory conditions. C. variopedatus, by comparison, is like $U$. caupo in that it is a filter-feeder living in a U-shaped tube and that it uses a mucus net to capture food. However, when kept in the laboratory in a glass or plastic tube, C. variopedatus secretes a natural 'parchment' burrow lining within this tube and typically forms normal 'caps' at each burrow opening (Riisgård 1989). The openings of these caps typically have a diameter much less than that of the portion of the burrow inhabited by the worm. Therefore, even in the laboratory, C. variopedatus may be able to create a comparatively normal burrow.

Although we made an effort to perform our recordings under ideal conditions, it is important to note some limitations of our measuring equipment and study design. First, we were only able to take measurements for 2 to $6 \mathrm{~h}$ after the worms were submerged by the tide (due to limitations of battery life and the necessity of keeping the electrical equipment dry), and therefore we cannot be certain that the behavior we recorded is representative of the remainder of the tidal cycle. Second, neighboring Urechis caupo burrows sometimes intersect with each other. To avoid this complication, we selected only worms within burrows that were not near any others. It is not clear how such intersections affect the irrigation behavior of worms in those burrows. Furthermore, while it was not an objective of this study to attempt to correlate burrow irrigation rate with environmental parameters such as algal biomass concentration, salinity, temperature (although this was monitored), and the presence or absence of commensals and predators, it is quite possible that at least some of these factors will ultimately prove to be important. The pumping behavior of Nereis diversicolor, for example, is significantly affected by temperature (Riisgård et al. 1992) and the concentration of algae in the overlying water (Vedel et al. 1994). Nonetheless, while the burrow irrigation activity of $U$. caupo in the laboratory is sensitive to changes in temperature, it is relatively insensitive to changes in food concentration (commercial marine invertebrate food at a concentration range of 0.36 to $36 \mathrm{mg} \mathrm{l}^{-1}$ ), ambient $\mathrm{PO}_{2}$, or low concentrations of hydrogen sulfide (Julian et al. 2001). It would be valuable to now determine whether these parameters affect the behavior of U. caupo in the field.

The metabolic rate of Urechis caupo during burrow irrigation has been measured under laboratory conditions (see Julian et al. 2001 for a review), but because 
the irrigation activity measured in the laboratory is generally much lower than under natural conditions, it is not clear whether these metabolic rate measurements are representative of the field metabolic rate. For example, if the lower irrigation rate in the laboratory was due strictly to increased flow resistance under experimental conditions, then the worms in laboratory studies may have been expending energy at a normal rate, although with less water flow resulting from it, and therefore the laboratory metabolic rate estimates may be representative of field rates. On the other hand, if the decreased irrigation rate was due to other experimental factors, as detailed above, then metabolic rates in the laboratory may be underestimates of field rates. Resolving this question will be critical in eventually understanding the caloric requirements and 'grazing impact' of $U$. caupo populations.

Currently, little is known about Urechis caupo's impact on coastal mudflat and estuarine environments, but the measurements of burrow irrigation behavior reported here suggest that it may be quite significant. If we assume that $U$. caupo pumps $266 \mathrm{ml} \mathrm{min}^{-1}$, each animal would pump $383 \mathrm{l} \mathrm{d}^{-1}$. If we also assume that every $U$. caupo feeds at $440 \mathrm{ml} \mathrm{min}^{-1}$ for approximately $33 \%$ of the time (the average flow rate and frequency of the sustained high-activity periods), then each worm would filter an average of $210 \mathrm{ld} \mathrm{d}^{-1}$. To date, the size and complete distribution of any $U$. caupo population has never been determined, but at Elkhorn Slough the average population density at the same intertidal zone used in our study has been estimated at 61 worms $\mathrm{m}^{-2}$ (Arp et al. 1992). At this density, U. caupo present in $1 \mathrm{~m}^{-2}$ would pump $23000 \mathrm{l} \mathrm{H}_{2} \mathrm{O} \mathrm{d}^{-1}\left(23 \mathrm{~m}^{3}\right)$ and clear the suspended material from over $13000 \mathrm{l} \mathrm{H}_{2} \mathrm{O} \mathrm{d}^{-1}$ $\left(13 \mathrm{~m}^{3}\right)$. Our preliminary estimates indicate that $U$. caupo populations cover hundreds of square meters (pers. obs.), suggesting that this animal has a substantial impact on the ecology of its estuarine and mudflat habitat.

Acknowledgements. We would like to thank Stephanie Wohlgemuth for providing her support and expertise on invertebrate ventilation, Harvey Lillywhite for loaning the flow meter to us, and Shirley Baker and Patrick Baker for helpful comments on the manuscript. We would also like to thank Alissa Arp and the members of the Romberg Tiburon Center for Environmental Studies and the members of the Moss Landing Marine Laboratory for assistance. The experiments complied with all guidelines of the University of Florida Institutional Animal Care and Use Committee.

\section{LITERATURE CITED}

Anderson JG, Meadows PS (1978) Microenvironments in marine sediments. Proc R Soc Edinb 76B: 1-16

Arp AJ, Hansen BM, Julian D (1992) The burrow environment

Editorial responsibility: Otto Kinne (Editor),

Oldendorf/Luhe, Germany and coelomic fluid characteristics of the echiuran worm Urechis caupo from 3 northern California population sites. Mar Biol 13:613-623

Fenchel T (1996) Worm burrows and oxic microniches in marine sediments. 1. Spatial and temporal scales. Mar Biol 127:289-295

Fisher WK, MacGinitie GE (1928) A new echiuroid worm from California. Ann Mag Nat Hist 1:199-204

Grove MW, Finelli CM, Wethey DS, Woodin SA (2000) The effects of symbiotic crabs on the pumping activity and growth rates of Chaetopterus variopedatus. J Exp Mar Biol Ecol 246(1):31-52

Gursul I (1998) Incompressible laminar and viscous flows. In: Johnson RW (ed) The Handbook of fluid dynamics. CRC Press, Boca Raton, FL, p 9.1-9.48

Hall VE (1931) The muscular activity and oxygen consumption of Urechis caupo. Biol Bull 61:400-416

Jørgensen CB (1955) Quantitative aspects of filter feeding in invertebrates. Biol Rev 30:391-454

Jørgensen CB, Møhlenberg F, Sten-Knudsen O (1986) Nature of relation between ventilation and oxygen consumption in filter feeders. Mar Ecol Prog Ser 29:73-88

Julian D, Arp AJ (1992) Sulfide permeability in the marine invertebrate Urechis caupo. J Comp Physiol 162(B):59-67

Julian D, Chang ML, Judd JR, Arp AJ (2001) Influence of environmental factors on burrow irrigation and oxygen consumption in the mudflat invertebrate Urechis caupo. Mar Biol 139(1):163-173

Krüger F (1964) Messungen der Pumptätigkeit von Arenicola marina L. im Watt. Helgol Wissenschaftliche Meeresunters 11/12:70-91

Lawry JV (1966) Neuromuscular mechanisms of burrow irrigation in the echiuroid worm Urechis caupo (Fisher and MacGinitie). I: Anatomy of the neuromuscular system and activity of intact animals. J Exp Biol 45:343-356

MacGinitie GE (1945) The size of mesh openings in mucus feeding nets of marine animals. Biol Bull 88:107-111

Meyers MB, Fossing H, Powell EN (1987) Microdistribution of interstitial meiofauna, oxygen and sulfide gradients, and the tubes of macro-infauna. Mar Ecol Prog Ser 35:223-241

Pritchard A, White FN (1980) Metabolism and oxygen transport in the innkeeper worm Urechis caupo. Physiol Zool $54: 44-54$

Riisgård HU (1989) Properties and energy cost of the muscular piston pump in the suspension feeding polychaete Chaetopterus variopedatus. Mar Ecol Prog Ser 56:157-168

Riisgård HU (1991) Suspension feeding in the polychaete Nereis diversicolor. Mar Ecol Prog Ser 70:29-37

Riisgård HU, Banta GT (1998) Irrigation and deposit feeding by the lugworm Arenicola marina, characteristics and secondary effects of the environment. A review of current knowledge. Vie Milieu 48(4):243-257

Riisgård HU, Larsen P (1995) Filter-feeding in marine macroinvertebrates: pump characteristics, modelling and energy cost. Biol Rev 70:67-106

Riisgård HU, Vedel A, Larsen PS (1992) Filter-net structure and pumping activity in the polychaete Nereis diversicolor: effects of temperature and pump-modelling. Mar Ecol Prog Ser 83:79-89

Vedel A, Riisgård HU (1993) Filter-feeding in the polychaete Nereis diversicolor: growth and bioenergetics. Mar Ecol Prog Ser 103:91-101

Vedel A, Andersen BB, Riisgård HU (1994) Field investigations of pumping activity of the facultatively filter feeding polychaete Nereis diversicolor using an improved infrared phototransducer system. Mar Ecol Prog Ser 103:91-101

Submitted: May 8, 2002; Accepted: October 4, 2002

Proofs received from author(s): November 13, 2002 